\title{
Central and peripheral $\beta$-adrenergic control of gastrointestinal motility in sheep
}

\author{
P Brikas, J Fioramonti, L Buéno
}

Department of Pharmacology, INRA, 180, chemin de Tournefeuille, 31300 Toulouse, France

Introduction - Some effects of $\beta$ adrenoceptor agonists on gastrointestinal motility have been investigated in monogastric species (Burks, 1987). Several side effects of $\beta$-blockers are mediated through the central nervous system which is involved in the control of gastrointestinal motility. This study was undertaken to determine the central and peripheral actions of $\beta_{1}$ - and $\beta_{2}$ - agonists on forestomach, abomasal and intestinal myoelectrical activity in sheep.

Materials and Methods - Four ewes were chronically fitted with an intracerebroventricular (icv) cannula and intraparietal electrodes in the reticulum, the caudodorsal and ventral blind sacs of the rumen, the great curvature of the abomasum, the duodenal bulb and the proximal jejunum.

Results and Discussion - Intravenous (iv) infusion of the $\beta_{1}$-agonist dobutamine (Lilly France, St Cloud; $30 \mu \mathrm{g} / \mathrm{kg} / \mathrm{min}, 15$ $\mathrm{min}$ ) decreased the frequency of reticular, ruminal and abomasal contractions, increased the number of contractions on the duodenal bulb (fig 1), and induced a phase of intense spiking activity (phase 3) on the jejunum. These effects were reproduced by an icv administration of dobutamine $(10 \mu \mathrm{g} / \mathrm{kg})$ and were blocked by acebutolol, a specific $\beta_{1}$-antagonist, given iv (1 $\mathrm{mg} / \mathrm{kg}$ ) or icv $(0.1 \mathrm{mg} / \mathrm{kg}$ ). Ritodrine (Duphar, Weesp, NL) a $\beta_{2}$-agonist, infused iv (10 $\mu \mathrm{g} / \mathrm{kg} / \mathrm{min}, 15 \mathrm{~min}$ ), did not modify forestomach and jejunal motility but strongly reduced the frequency of abomasal contractions (fig 1). This effect was blocked by propranolol given iv ( 0.5 $\mathrm{mg} / \mathrm{kg}$ ) but not icv $(0.05 \mathrm{mg} / \mathrm{kg})$ and was not modified by acebutolol (1 mg/kg, iv). Ritodrine icv (15 $\mu \mathrm{g} / \mathrm{kg})$ did not modify the motility of all the sites investigated. It is concluded that $\beta_{1}$-agonists act at the level of the central nervous system to inhibit the motility of the forestomach and abomasum and to stimulate the intestine, while $\beta_{2}$-agonists selectively inhibit abomasal motility through peripheral receptors.

Burks TF (1987) In: Physiology of the Gastrointestinal Tract (Johnson LR, ed) Raven Press, New York, 723-743

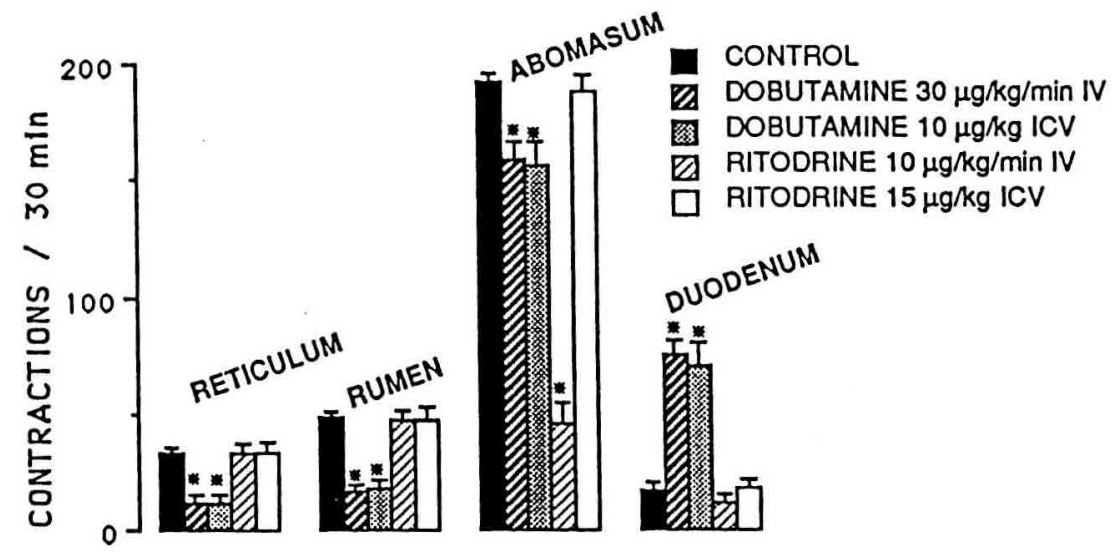

Fig 1. Changes in the frequency of spike bursts of the reticulum, the rumen, the abomasum and the duodenal bulb by dobutamine and ritodrine given iv or icv. 